\title{
Channeling health economics research initiatives to improve decision-making processes in the $\mathrm{EU}$
}

\author{
F. Antonanzas $\cdot$ R. Rodríguez-Ibeas
}

Received: 20 March 2013/Accepted: 2 April 2013/Published online: 11 April 2013

(C) Springer-Verlag Berlin Heidelberg 2013

Health economics as a specialization area has rapidly grown during the last 4 decades. Researchers have selected the topics according to a variety of issues, such as general scientific interest, background knowledge, and perceived gaps in the field as well as the relevance of the topics to their jurisdictions, among others.

On the part of the health authorities (managers and politicians), they have to cope with a variety of real-life types of problems that need to be addressed. In their daily practice, they have at their disposal instruments and information from the health economics literature to better manage their health systems.

Nevertheless, some mismatches exist in the activities developed by these two groups. On the one hand, it is believed that health authorities disregard or do not use all the available information generated by researchers in their decision-making processes. This could be due to either the irrelevance of a given research for a specific health decision or because health authorities simply ignore it. On the other hand, researchers, for whatever the reason, do not address some topics that really matter to health managers and that would potentially improve the general efficiency of healthcare systems and increase social welfare.

The interest in assessing the value of research activities in support of health systems policies was highlighted by Buxton and Hanney 2 decades ago [1]. The need to cope with the gap between research and health policy has also been previously acknowledged by some authors and institutions such as the WHO [2-4]. However, the number of studies and their scope have been quite limited (addressing

F. Antonanzas $(\bowtie) \cdot R$. Rodríguez-Ibeas

Department of Economics, University of La Rioja,

26004 Logrono, Spain

e-mail: fernando.antonanzas@unirioja.es particular health areas such as pain [5], focusing on single Member States' research needs [6], being descriptive of some situations [7], and dealing with specific research venues - such as the economic evaluation of health technologies [8] and the value of information as a technique to establish research topics in economic evaluation [9]). More recently, Hunter and Brown [10] have reviewed research topics within the field of health management, and Debrand and Dourgnon [11] described the relationships between health economics research and health policies debated in a meeting of experts from several countries; they also emphasized the need for "using research evidence to produce pertinent and efficient tools for health policymaking." In spite of these efforts, there is a lack of systematic analysis (follow-up or periodic reviews) on this topic so that health research can be channeled to the more useful areas of health policy making. Other authors have recently noted the necessity to fill the gap between health research and policy [12].

Interestingly, health economics scientific policy in most of the EU countries usually relies on public calls as the instruments to channel funds to research programs. However, these programs have vaguely defined goals and are commonly framed in rather general terms, either guided by some leading research teams or by politicians and bureaucrats in charge of the general scientific policy. Health authorities are not usually empowered to decide on or select the guiding principles of the general scientific policy (i.e., the goals of the calls for each program).

In this environment, it is a common practice for each research group to participate in the calls by proposing its preferred topics, which usually find a niche that makes their proposal eligible to receive financial aid. One frequent evaluation criterion to evaluate the results of a research project ex-post is to look at the quality of the peer-reviewed 
journals in which they are published. In the last instance, the number of disseminated outcomes, no matter whether as presentations in congresses, organization of seminars and meetings, or publications, justify by themselves the public investment in that research area, but a follow-up of the application of the results is rarely performed.

From the perspective of the decision-making processes, as health authorities are not directly involved in making the design about the scientific policy, they used to be reluctant or not very receptive to incorporating the new unsolicited information generated by the research community into their current activities. In summary, designing a clear health research policy that takes into account the actual needs of the health systems seems to be needed so that the generation of scientific knowledge covers the relevant topics. By doing this, one could expect the health authorities to make more extensive use of the scientific outputs provided by the research community. In this sense, some mechanisms should be designed to allow health authorities to play a more active role in the definition of the calls. As a result, they would be more motivated to back their managerial activities with the results from the so promoted research.

Since the EU Framework Programme for Research and Innovation Horizon 2020 [13] is preparing the launch of next calls, we take advantage of this important event to reflect a little on the necessities of the health systems across the EU and, if possible, to help redirect research efforts to the main challenges health systems face. In this sense, we focus on detecting the most frequently addressed topics by researchers and on the health policy issues currently faced by health systems where health economics could provide scientific answers.

In order to establish the relationships between the health economics topics more frequently studied by researchers and the main concerns of health authorities, in a broad sense, we have simultaneously undertaken a literature search in several health economics journals and sent a short survey to some leading experts on their domestic healthcare systems. In particular, we have reviewed the table of contents of six major health economics journals (Pharmacoeconomics, European Journal of Health Economics, Health Policy, Value in Health, Health Economics, and Health Economics, Policy and Law) from 2008 to 2013 and classified their publications according to a list of several topics. The selection criteria were that the journals had to publish health economics, health policy, and health management issues, have a high impact factor, and mostly target European health systems (e.g., the Journal of Health Economics was not included in this review because a significant number of its articles addressed US health system issues). We initially selected a broad list of topics that included economic evaluations, management of health systems, and industrial economics. Later on, after checking the published articles, we divided some of the initial topics into the categories shown in Table 1. We also asked health economics experts from France, Italy, Germany, UK, The
Table 1 Selected topics and number of publications

Miscellaneous: it includes the articles that do not fall into any of the established topic categories as well as the articles that were difficult to classify

Pharm Pharmacoeconomics, EJHE European Journal Of Health Economics, $H E$ Health Economics, $V H$ Value in Health, HP Health Policy, HEPL Health Economics, Policy and Law

\begin{tabular}{lrrrrrrr}
\hline Topics & Journals & & & & & \\
\cline { 2 - 7 } & Pharm. & EJHE & HE & VH & HP & HEPL & Total \\
\hline Public-private insurance & & 13 & 8 & & 10 & 2 & 33 \\
Management based on efficiency evidence and & 7 & 4 & 6 & 3 & 87 & 19 & 126 \\
$\quad$ information systems & & & & & & & \\
Equity across regions-health & & 4 & 8 & & 19 & 15 & 46 \\
Sustainability of the system (budget) & 2 & 17 & 7 & 9 & 18 & 1 & 54 \\
Public and private health care & & 3 & 7 & & 4 & 6 & 20 \\
Copayments and equity & & 4 & 2 & 2 & 1 & 2 & 11 \\
Incentives and payments for human resources & & 9 & 14 & 33 & & 56 \\
Economic evaluation & & & & & & \\
$\quad$ Methodological & 83 & 27 & 49 & 147 & 3 & & 309 \\
Cases & 100 & 36 & 2 & 157 & 10 & & 305 \\
$\quad$ QALYs and preferences & 38 & 29 & 33 & 247 & & 347 \\
$\quad$ QALYs and monetary values & 5 & 9 & 20 & 9 & & 2 & 45 \\
$\quad$ Reviews & 58 & 3 & & 3 & 3 & 1 & 68 \\
Health industrial economics: price and reimbursement & 27 & 22 & 13 & 3 & 33 & 10 & 108 \\
$\quad$ and risk-sharing & & & & & & \\
Analysis of health systems (retrospective) & 2 & 2 & 5 & 68 & 15 & 92 \\
Cost of illness & 41 & 47 & 13 & 40 & 2 & 1 & 144 \\
Economic evaluation and its application to regulation & 25 & & 2 & 45 & 39 & 111 \\
Miscellaneous & 19 & 53 & & 29 & 38 & 12 & 151 \\
\hline
\end{tabular}


Netherlands, and Spain about their opinions concerning the current challenges of their systems. With this information, we elaborated a list of the main issues faced by national health systems. Finally, by comparing both types of information, we determined whether the research interests of the scientific community match the needs of current health systems. In case of a mismatch, the scientific policy (for instance, through the aforementioned EU Framework Programme Horizon 2020) can then be designed to fill in the gap.

\section{Main findings about the research topics}

The results of our field study are summarized in Table 1. Most articles dealt with the economic evaluation of health technologies (about $50 \%$ ). They mainly focused on methodological issues directly applied to the evaluation of a given technology (about one third of them) and pure costeffectiveness or cost-utility analyses (another one third). Likewise, the analysis of the quality-adjusted life-years and patient preferences have received much attention (one third again), as have cost of illness analyses (about $5 \%$ of the total). The remaining themes have received much less attention by researchers, outstanding the applications of economic evaluation to regulatory questions and the managerial issues connected to efficiency evidence and information systems (about $5 \%$ each one). Other topics such as private-public insurance, equity analysis (individual copayments and geographical considerations), budgetary management to maintain the sustainability of the system, and human resource incentives are scarcely represented in the publications (less than $2.5 \%$ each). The interactions between the healthcare system and the private providers reflected in price and reimbursement regulations and in other institutional arrangements such as those analyzed by industrial economics have not earned much attention in the literature (about $5 \%$ in total).

When we take a closer look at journal contents, differences in the types of topics addressed clearly arise. This was expected given the specializations of the reviewed journals. For instance, Pharmacoeconomics and Value in Health mostly covers economic evaluation topics and cost of illness analyses (totaling over $75 \%$ of their printed papers). However, these topics were little represented in the journals Health Policy and Health Economics, Policy and Law (less than $2 \%$ of the articles), while in the European Journal of Health Economics and Health Economics that proportion was 37 and $55 \%$, respectively. The topics most frequently analyzed in Health Policy were the managerial issues connected to efficiency evidence and information systems (87 articles that represented $70 \%$ of all the recorded publications), retrospective studies of healthcare systems (68 articles, comprising $74 \%$ of all papers on this topic), incentives for human resources (33 articles, almost $60 \%$ of all publications reviewed), and the interactions between efficiency studies and regulation (39 papers out of 111). Health Economics and the European Journal of Health Economics contain a more proportional balance of areas, although economic evaluation issues still dominate their contents. Regarding the journal Health Economics, Policy and Law, its emphasis is on managerial issues (19 papers), geographical equity of the systems (15 papers out of 46 reviewed texts), and the analysis of healthcare systems (15 publications, about $17 \%$ of all the reviewed papers). Interestingly, Health Economics, Policy and Law is a recent journal containing many articles dealing with legal aspects, which were not considered relevant topics for this search unless clear connections with regulatory issues and policy recommendations were detected.

We have also observed the trends in the frequency of the themes analyzed in the reviewed publications (not shown in the tables). In general, it can be stated that there has been an increase in the number of cases of economic evaluations and cost of illness type studies as well as in the analysis of QALYs and health preferences, with Value in Health, Pharmacoeconomics, and the European Journal of Health Economics being the journals selected by the researchers. It is remarkable that Value in Health and Health Policy have also increased the number of studies devoted to economic evaluation and regulation (mainly in the last years). The attention paid to incentives and payment systems for human resources in the 2012 issues of Health Policy should also be mentioned. The journal Health Economics, Policy and Law has also experienced an increase in the number of articles related to the analysis of healthcare systems in the last year. With respect to the other topics and journals, no special trends were found.

\section{Main challenges facing the healthcare systems}

With regard to the healthcare issues mentioned by the experts, the main challenges facing healthcare systems are shown in Table 2. It can be observed that organizational and managerial aspects of the health systems are a recurrent concern in all countries. Related to them, incentives and payment systems to human resources as well as their planning are considered of capital importance to increase the productivity of the system and, in summary, to obtain more care with lower costs.

Another topic that requires attention has to do with equity issues from several perspectives: individual (when different copayments are established), access to the system (depending on the type of insurance and citizenship status), 
Table 2 Health economic issues across Europe

\begin{tabular}{|c|c|}
\hline Country & Healthcare issues \\
\hline France & $\begin{array}{l}\text { Funding of telemedicine in a health system based on a fee-for-service approach (DRG in hospital and per-procedure fee in } \\
\text { ambulatory care) } \\
\text { Organizational and managerial issues. Payment systems for health professionals } \\
\text { Funding of public hospitals: optimal mix of DRGs and general annual budget } \\
\text { Coverage for uninsured persons and equity of access } \\
\text { Health technology assessments } \\
\text { CE threshold(s) based on GDP, categories of services or goods (devices and drugs), and of target population (age and severity of } \\
\text { conditions) }\end{array}$ \\
\hline Italy & $\begin{array}{l}\text { Efficiency and equity across regions } \\
\text { Health technology assessment (better instruments to assess technologies and to apply them) } \\
\text { Incentives to health staff } \\
\text { Information network to avoid repetition of tests and improve budget impact (organizational and managerial issues). Budget } \\
\text { control } \\
\text { Private-public relationships (rich out of the system?) }\end{array}$ \\
\hline Germany & $\begin{array}{l}\text { Two classes of insured people (private, public) adverse selection problems } \\
\text { Parallel export of drugs and pricing policies } \\
\text { Organ transplantation management } \\
\text { Incentives to consultants in clinics. Clinical management } \\
\text { Fair invoicing to medical insurances }\end{array}$ \\
\hline UK & $\begin{array}{l}\text { Funding the system on a long-term basis } \\
\text { Copayments and welfare. Co-payment principles for expensive treatments such as cancer therapies } \\
\text { Primary care and hospital reforms: DRGs, transferring risk and funds } \\
\text { Information systems to improve performance of the system and incentives to human resources management } \\
\text { Alternative analytical frameworks to the cost/QALY approach for treatments for ultra-rare diseases and for 'innovative' } \\
\text { treatments, e.g., social willingness to pay, taking equity and justice principles into account. } \\
\text { Value-based and cost-effectiveness thresholds } \\
\text { In general, the recent mandate issues (as stated in November 2012) }\end{array}$ \\
\hline Spain & $\begin{array}{l}\text { Copayments and equity } \\
\text { Private and public management of care. Chronic patient management } \\
\text { New public insurance and equity (migrants) } \\
\text { Budget control. Setting economic evaluation as a tool in P\&R and in managerial decisions } \\
\text { Productivity of the system and innovation incentives } \\
\text { Human resources planning } \\
\text { Benefit package-reducing spending on low clinical value treatments (Croydon list) } \\
\text { Health determinants }\end{array}$ \\
\hline $\begin{array}{l}\text { The } \\
\text { Netherlands }\end{array}$ & $\begin{array}{l}\text { Transition from public to private healthcare system } \\
\text { Integration of various types of care ("case manager," Dutch term: "ketenzorg") } \\
\text { Conditional reimbursement for expensive treatments } \\
\text { Introduction of DRGs in the hospitals and discussions on whether to include expensive drugs (oncology, rheumatology, and } \\
\text { HIV, for example) in these DRGs } \\
\text { Inclusion of cost-effectiveness in the regulation of public reimbursement and possible extension to diagnostics and medical } \\
\text { devices }\end{array}$ \\
\hline
\end{tabular}

and regional (variations in access to the system and in the medical practice). This concern is mostly noted by experts from regionalized systems. Private-public relationships between healthcare providers also constitute a major concern in some countries (Italy and Spain). Funding and budget control issues are also constant preoccupations of the healthcare systems. In this sense, instruments to guarantee the efficiency of the decisions and their application to new regulations have also been highlighted by the experts of several countries (in particular, value-based pricing, cost-effectiveness implementation in pricing, and reimbursement decisions and thresholds figures, improving the 
information of the efficiency of health technologies, etc.). The importance of the DRGs in several countries and how to incorporate them into the funding and management of hospitals was also noted in the survey.

In addition to these common concerns, there are some issues specific to particular health systems. This is the case in the UK, which has recently elaborated a "Mandate from the government to the NHS" setting the main health goals for the next 2 years [14]. Germany would like to analyze the improvement of its transplantation system; France is projecting the implementation of telemedicine in a more generalized way. Spain aims to incorporate an economic evaluation in the standard decision-making processes-the price and reimbursement of technologies as well as in some clinical protocols and managerial decisions-and to establish a health benefit package (or delisting of some of the existing low-efficacy treatments). Italy addresses the need of using information networks to improve the efficiency of the system by avoiding repeated tests. The Netherlands system is rather concerned with the integration of various types of care ("case manager," ketenzorg) and with conditional reimbursement for expensive treatments.

\section{Does published research match experts' concerns?}

According to the above descriptions, it can be said that there are some challenges facing national healthcare systems that have already received the required attention in the literature. This is the case for economic evaluation (including specific health technologies, QALYs studies, and methodological developments), which is the main topic of a significant number of the publications. Efficiency information is useful to orient clinical practice and regulatory processes, although some further research may be needed to improve the methodology to define acceptance thresholds, quality-of-life monetary values, and the management implications of the efficiency outcomes found in the evaluations. This research area dominates the reviewed publications and very likely will continue to do so in the future. In a sector very open to innovations, evaluations of new technologies are a must for the efficiency of the systems and will continue to be required by health authorities in the next years in order to make decisions with optimal information.

A clear worry concerning the systems is making them sustainable and better managed. A limited number of publications (about 180) were found on this topic. Information systems incorporate useful data to understand the productivity of the resources and to improve management, but still many more analyses must be done in the area. Furthermore, since each health system has its own features, there is room for more specific research adapted to each jurisdiction. We believe that this research venue should be promoted.

However, there are other issues that have not been sufficiently addressed in the literature. For example, 56 published articles dealt with payments to health staff, and we did not find any reference to this theme in three of the revised journals. Again, incentives for human resources are crucial to increase the productivity of the systems and to make them more efficient. Therefore, it is clear that more research should be devoted to the study of payment systems adapted to each organization.

Although the consulted experts declared that equity issues are important for their systems, the topic has received little attention in the literature (57 articles). The importance of the topic derives from the fact that most of the countries in the EU have a public health system and their constitutions usually declare the right to universal healthcare for all citizens, regardless of any personal features (race, religion, sex, etc.). Any departure from equity across either patients or regions would be unacceptable (even illegal in some countries).

Related to the equity topic, co-payments have consequences for equity, which have rarely been studied; in any event, their results are difficult to transfer from the original jurisdiction where the study was developed to another one. Hence, specific region-by-region research would be useful to understand the consequences of co-payment policies on consumer-patient behavior to better support public decisions. Moreover, co-payments also have implications for the efficiency of the system (resource allocation and the like), and their analysis would provide some orientation concerning the suitability of the policies in this area. Once again, more research is needed on this matter.

We also found some papers on health industrial economics (mainly price and reimbursement, value-based pricing, etc.) and also on the effects of economic evaluation studies on regulatory decisions (about 220 papers in total). This research area seems to match experts' opinions on the necessities of the systems and will probably be maintained in the future as these connections are key for translating the theory (information accrued by the studies) into practice (the efficiency and the sustainability of the systems). It would be interesting to maintain the research activities linked to this field.

Consulted experts also pointed out some interesting aspects that current health systems policies are addressing and where some foundations to support those decisions would be most appreciated. This is the case of the funding of public hospitals based on DRGs and the risk transfers between primary care and specialized care. Likewise, the relationships between private and public healthcare as well as private and public insurance were also highlighted by some experts as important topics to be studied. Our 
literature review found few references to these areas. Hence, some efforts should be redirected to learn more about these issues.

\section{Concluding remarks}

Although much research has been published in the health economics area (over 2,000 papers in the 6 selected major journals in the last 5 years), we found that the topics the researchers select do not fully cover all the challenges health systems face (private-public relationships, co-payments and equity issues, incentives to human resources, information systems, efficient management, etc.). There is an unmet need to be covered in several areas, and some measures should be adopted. In this sense, it would be desirable to take advantage of the next EU Framework Programme Horizon 2020 to list the required topics to be addressed; as been pointed out above, some of them are common to several countries, and others pertain to specific health systems. Besides the previously suggested more active role of health authorities to participate in the selection of the themes for the new calls for research projects, it would be desirable that they take advantage of the fair amount of scientific knowledge that is published annually in health economics journals. Almost everyone can give examples of recent decisions adopted in his or her own national health system that have explicitly ignored the available scientific evidence. How discouraging for the scientific community and what a pity for the systems!

Acknowledgments The authors thank the following health economics experts for their participation in this small survey of the current challenges of their national healthcare systems: Prof. Y. Zölner (University of Hamburg, Germany), F. Fagnani (CEMKA-EVAL, France), Prof. S Capri (University Carlo Cattaneo-LIUC, Italy), K. Tolley (Tolley Health Economics, Ltd., UK), Prof. M. Postma (University of Groningen, The Netherlands), Prof. V. Ortún (University Pompeu
Fabra, Spain), and Prof. J. Oliva (University of Castille-La Mancha, Spain).

\section{References}

1. Buxton, M., Hanney, S.: How can payback from health services research be assessed? J Health Serv Res Policy 1, 35-43 (1996)

2. Fleurence, R.L., Torgerson, D.J.: Setting priorities for research. Health Policy 69, 1-10 (2004)

3. Directorate-General for Research Special issue on health care. European Foresight Monitoring Network. EU 24044 EN. European Commission. Brussels (2009)

4. WHO: Report from the Ministerial Summit on Health Research: identify challenges, inform actions, correct inequities. Geneva, Switzerland, WHO 2004 www.who.int/rpc/summit/documents/ summit_report_final2.pdf

5. Harding, R., Gomes, B., Foley, K.M., Higginson, I.J.: Research priorities in health economics and funding for palliative care: views of an International Think Tank. J Pain Symptom Manage 38(1), 11-14 (2009)

6. Bernal-Delgado, E., Peiró, S., Sotoca, R.: Prioridades de investigación en servicios sanitarios en el Sistema Nacional de Salud. Una aproximación por consenso de expertos. Gac. Sanit. 20(4), 287-294 (2006)

7. Tallon, D., Chard, J., Dieppe, P.: Relation between agendas of the research community and the research consumer. Lancet $\mathbf{3 5 5}$, 2037-2040 (2000)

8. Hoffman, C., Stoykova, B.A., Nixon, J., Glanville, J.M., Misso, K., Drummond, M.F.: Do health care decision makers find economic evaluation useful? Value Health 5(2), 71-78 (2002)

9. Claxton, K., Sculpher, M.J.: Using value of information analysis to prioritise health research: some lessons from recent UK experience. Pharmacoeconomics 24, 1055-1068 (2006)

10. Hunter, D.J., Brown, J.: A review of health management research. Eur J Public Health 17(supplement 1), 33-37 (2007)

11. Debrand, T., Dourgnon, P.: Building bridges between health economics research and public policy evaluation. Expert Rev Pharmacoecon Outcomes Res 10(6), 637-640 (2010)

12. Hanney, S.R., Gonzalez-Block, M.A.: Yes, research can inform health policy; but can we bridge the "Do-knowing it's been done" gap? Health Res Policy Syst 9, 23 (2011)

13. http://ec.europa.eu/research/horizon2020/

14. https://www.wp.dh.gov.uk/publications/files/2012/11/mandate.pdf 